\title{
Influence of the volute on the flow in a centrifugal compressor of a high-pressure ratio turbocharger
}

\author{
X Q Zheng ${ }^{1 *}$, J Huenteler ${ }^{2}$, M Y Yang ${ }^{1}$, Y J Zhang ${ }^{1}$, and T Bamba ${ }^{3}$ \\ ${ }^{1}$ State Key Laboratory of Automotive Safety and Energy, Tsinghua University, Beijing, People's Republic of China \\ ${ }^{2}$ RWTH Aachen University, Germany \\ ${ }^{3}$ IHI Corporation, Corporate Research and Development, Yokohama, Japan
}

The manuscript was received on 15 January 2010 and was accepted after revision for publication on 20 July 2010.

DOI: 10.1243/09576509JPE968

\begin{abstract}
The asymmetric influence of the volute on the flow in a transonic, high-pressure ratio centrifugal compressor at off-design conditions was investigated. Fully three-dimensional viscous steady-state computational fluid dynamics (CFD) was applied to simulate the flow in a 4.2:1 design pressure ratio compressor for automotive application. Computed performance characteristics are presented for low- and high-pressure ratio operating conditions, with and without an overhung volute. The volute was found to severely harm aerodynamic stability of the investigated compressor when operating at lower than design mass flow. The relative narrowing effect of the volute on compressor map width increases with pressure ratio up to a 42 per cent drop in stable flow range at design speed. The inter-passage variations in performance quantities and the influence of the volute tongue region are discussed in detail. The circumferential variations of incidence angle correlate with rotational speed, which, in combination with the higher sensitivity to incidence angle at transonic inflow conditions, seems to deteriorates stability when transonic inflow conditions are reached.
\end{abstract}

Keywords: high-pressure ratio, turbocharger, transonic flow, centrifugal compressor, volute

\section{INTRODUCTION}

With an increase in power as primary motivation, turbocharging was used in diesel engines since the beginning of their history. In recent decades, this technology spread out from industrial and maritime applications to mobile small displacement engines, as they are used in automotive applications. A high power density and therefore a high turbocharger pressure ratio is necessary to fulfill requirements introduced by recent engine developments, i.e. for:

(a) significant downsizing;

(b) $\mathrm{NO}_{x}$ treatment by engine control means of high exhaust gas recirculation rates;

(c) the facilitation of high-altitude operation.

\footnotetext{
* Corresponding author: State Key Laboratory of Automotive Safety and Energy, Tsinghua University, Beijing, People's Republic of China.

email:zhengxq@tsinghua.edu.cn
}

As single-stage centrifugal compressors facilitate a high pressure ratio at small spatial requirements, they are used in the majority of turbochargers.

If the pressure ratio of a centrifugal compressor exceeds approximately 3.5, the Mach number relative to the inducer of the impeller will be larger than 1.0. If the pressure ratio exceeds 4.5 , even the flow downstream of the impeller can be expected to be supersonic [1]. High relative inlet velocities facilitate high specific work input; however, the range is narrowed as the incidence angle at stall inception decreases with relative Mach number at the inlet. This effect of constricting the operation range at a large torque is of utmost significance for automotive applications, as they demand for high torque over a wide mass flow range and frequently operate at off-design conditions. The widening of the stable flow range (SFR) is hence a major issue for high pressure ratio compressor design for automotive turbocharging.

The improvement of centrifugal compressor performance requires a good understanding of the flow mechanisms and an accurate prediction of the flow pattern inside the volute. Detailed measurements 
by Ayder et al. indicated a very complex, threedimensional (3D) flow within the volute and gave fundamental insights for further research [2-4]. It is well known that the volute flow causes a rotationally non-symmetric pressure distribution in the diffuser outlet at off-design conditions: the volute acts as a diffuser at lower than design mass flow and as a nozzle at higher than design mass flow, respectively. This circumferential asymmetry has been recognized and intensive experimental investigations of the flow within the volute and the propagation of the distortions into upstream components were carried out for subsonic compressor units $[\mathbf{5}, \mathbf{6}]$. The work of Sorokes et al. [5] first confirmed that the pressure nonuniformity extends upstream of the impeller, implying that the impeller is subject to varying inlet and exit conditions, deteriorating performance and stability.

Limited measurement technology and its high costs make numerical analysis necessary. Early $1 \mathrm{D}$ and 3D simulations were sufficient to reproduce results obtained from measurements [7-11]. Since the beginning of this decade, 3D CFD resolution is high enough for detailed flow analysis. The first work that introduced phenomena not yet reported from experiments was published by Gu et al. in 2001, whose work helped understand the influence of the volute on impeller performance $[12,13]$. At off-design conditions, they identified an effect of mass flow-dependent direction of boundary layer mergence and an asymmetric distortion of the passage flow caused by variations in static pressure slope at the impeller exit. The latter effect causes each single passage to operate at a different operating condition at each point of time. They concluded that circumferentially increasing static pressure in direction of rotation at the impeller exit is disadvantageous for the performance of subsonic centrifugal compressors.

Based on the gained insights about the volute and its influence, different approaches were investigated to decouple the compressor from the volute influence or to diminish its impact, respectively. Installing low solidity vanes in the diffuser as a method to reduce the impact of the static pressure distribution on the impeller flow field was introduced by Sorokes and Koch [14]. Steglich et al. [15] developed an asymmetric diffuser with an internal volute. How different volute design parameters influence performance and efficiency has recently been investigated by several authors [16-20], some of which focused on the tongue area of the volute and how to optimize its design [21, 22]. The latest work of Dai et al. (2010) showed how different volute designs impact the influence of the volute tongue region on the flow field of a subsonic compressor at off-design conditions [20].

Since the stall-free angle of incidence is a function of inducer Mach number, the flow field of high pressure ratio compressors is expected to exhibit a significantly higher sensitivity to the named downstream asymmetries. Extensive research work has been done on the topic of stall precursors, as well as on parametric optimization of performance and SFR. The volute has also been subject to examinations considering all three aspects. However, when it comes to high pressure ratio compressors, knowledge about how the volute affects compressor operation is still limited.

In this work, the flow field in a high pressure ratio centrifugal compressor was simulated using $3 \mathrm{D}$ fully viscous steady-state CFD with Reynolds-averaged Navier-Stokes (RANS) equations for performance prediction. The simulation was validated with test bench results and then rerun without the volute. The results were compared and the volute influence analysed in detail.

\section{FLOW MODELLING AND SIMULATION PROCEDURE}

\subsection{Numerical model}

The simulation was done with NUMECA FINE/ Turbo $^{\mathrm{TM}}$ as interface for the EURANUS ${ }^{\mathrm{TM}}$ solver. The solver applies a CFD code based on a 3D steady compressible, finite volume scheme to solve RANS equations in conservative formulation. In order to obtain a sufficient shock wave and viscosity resolution, spatial discretization used in this work was done with a central scheme (based on reference [23]). For temporal discretization, a fourth-order Runge-Kutta scheme was applied [24]. Convergence of the solver was accelerated by enlarged Courant number at higher mass flows, relaxation of outlet pressure adaptation at lower mass flow, and application of a multi-grid procedure $[25,26]$.

The Spalart-Allmaras (S-A) one-equation model was chosen for turbulence closure $[\mathbf{2 7}, \mathbf{2 8}]$. The interface was modelled as frozen rotor (i.e. the rotating system is calculated in relative co-ordinates and the flow quantities are transferred over the interface without varying the relative position of impeller and the volute).

\subsection{Meshing}

Spatial discretization error is closely connected to the grid number. The topology was meshed with a resolution in compliance to the desired output variables: a very fine mesh was created for the flow field analysis and a coarse mesh for the calculation of performance characteristics. However, as a full passage simulation including the volute requires enormous CPU time per operation point, its influence on claimed time and memory resources could not be neglected. Several tests were carried out to analyse which lowest grid number still delivers accurate results. It was decided that 300000 nodes in one passage is an appropriate 
grid number for performance and stability analysis. For detailed flow analysis, a fine grid was set up with a higher grid number to attain a higher resolution of flow quantities. The final grid for one passage consists of ten blocks with 375642 (fine: 625 154) cells. The whole compressor grid including nine impeller passages, diffuser, and volute has 124 blocks and 3459304 (6342 040) cells. As recommended by the software provider, the grid exhibits a minimal grid quality as defined by measures of orthogonality (especially at the block boundaries; minimum $10^{\circ}$ ), relative grid spacing in boundary layers (expansion ratio $\leqslant 3$ ), grid skewness (aspect ratio $\leqslant 5000$ ) either within a certain block or between two different blocks [29].

A multi-block structured grid was defined to predict performance characteristics appropriately, with a boundary layer resolution sufficiently fine for the S-A model $\left(y_{1}^{+} \leqslant 10\right)$. The first node in the volute was positioned at a distance of $y_{\text {wall }}=3.5 \mathrm{E}-006 \mathrm{~m}$. A value of $1 \mathrm{E}-006 \mathrm{~m}$ was iteratively found to be appropriate for hub and diffuser endwalls. For the blades, the initial spacing had to be further reduced to $5 \mathrm{E}-007$. The resulting distribution of local values of $y_{1}^{+}$for the coarse mesh is shown in Fig. 1; the local values vary between approximately 1 and 5 , which fulfils the model's requirements.

The rotor-stator interface of the diffuser and volute was located at 126 per cent tip radius for reasons of meshing and to avoid numerical problems with the complex flow field at the impeller outlet. When meshing only the impeller passage without the volute, the diffuser outlet was relocated to 152 per cent tip radius to minimize the influence of the imposed outlet boundary conditions. The impeller hub and shroud were assumed to be contiguous at the rotor-stator connection to the volute; no leakage flow is simulated. A constant tip clearance of $t=0.0033 D$ was assumed, where $D$ is the trailing edge (TE) diameter.

Hub, diffuser backwall and blade patches

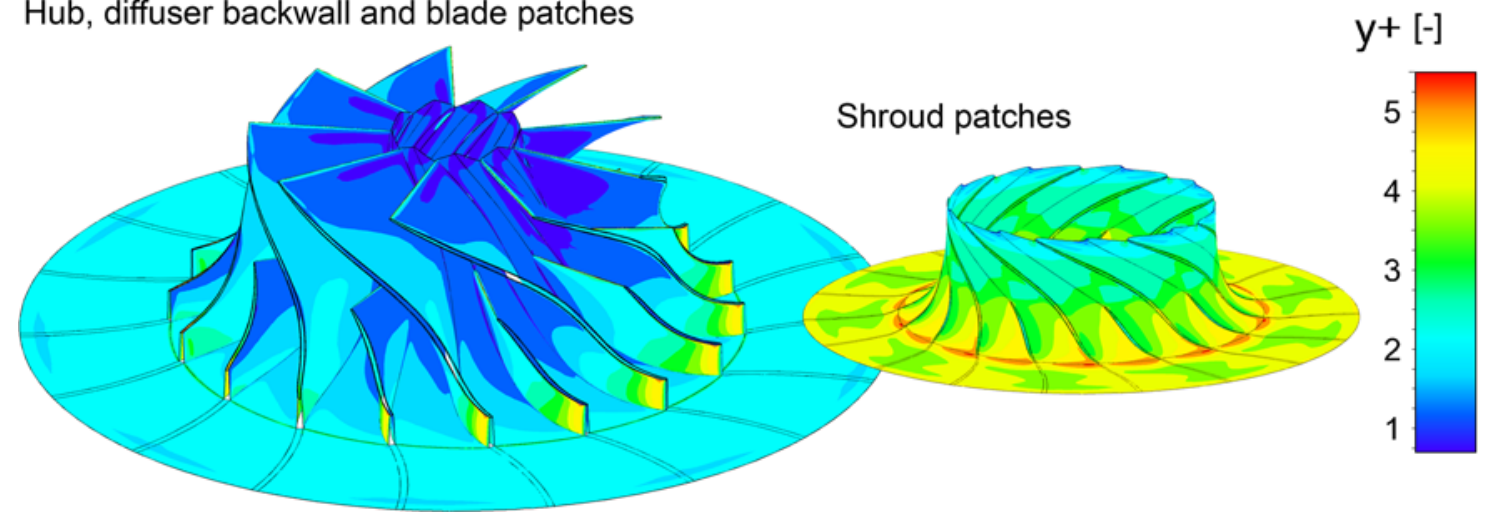

Fig. 1 Distribution of $y^{+}$on solid walls of hub, blades, and shroud

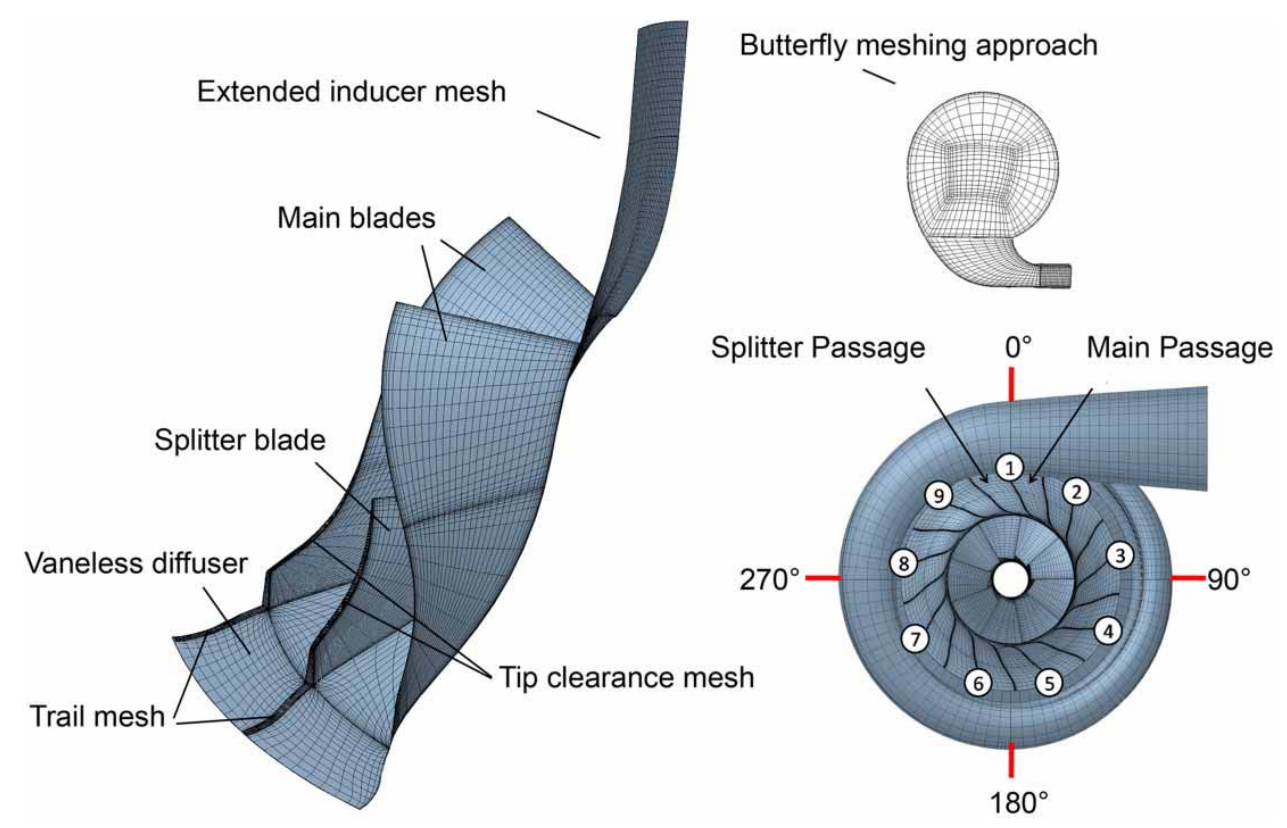

Fig. 2 Created mesh in detail: passage mesh projected on solid walls (left), butterfly meshing approach in volute cross-section (top right), passage numbering (below right), and angular mesh orientation 
To mesh the overhung volute, a butterfly mesh is applied in order to augment the orthogonality of the boundary layer cells. In Fig. 2, the passage mesh (projected on rotating solid walls), a cross-section of the volute mesh, and the whole mesh of the compressor are displayed.

\subsection{Simulation procedure}

Boundary conditions were set in accordance with the 1D characteristic theory. Total pressure, temperature, and velocity components were imposed at the inlet. At the outlet an average static pressure was imposed near choke and self-adaptive mass flowrate at other operating conditions. In case of flow re-entering the domain, the averaged total temperature of the outgoing flow is imposed on the backflow. To obtain the speed lines, near the choke the static exit pressure was raised from one simulation step to the next. In operating conditions with a high pressure ratio, the mass flow at the outlet was imposed and decreased from one simulation to the next. Both impeller and volute were set as adiabatic non-slip boundaries.

To create an initial solution for the calculation on the finest grid level, the simulation was first carried out to multi-grid level one (the second finest grid). For the first simulation of each rotational speed, simple estimations were made for velocity components and temperature for the whole domain. Subsequently, the result of each operation point was used as the initial solution for the next higher backpressure.

\subsection{Hardware and test bench specification}

The high pressure ratio radial compressor was designed with nine blades and nine splitter blades (located at 43.7 per cent in downstream axial direction), respectively. At design operation, the flow at the leading edge tips of the impeller exhibits a Mach number of approximately 1.2. The design speed of the tested compressor is $136000 \mathrm{r} / \mathrm{min}$, the pressure ratio is 4.2 and the design mass flowrate is $0.325 \mathrm{~kg} / \mathrm{s}$. The main blades' and splitter blades' TE are designed blunt. The backsweep angle (angle between hub and TE in meridional direction) is $-35^{\circ}$; the blades are unshrouded. Tip clearance is assumed to be meridionally constant with a width of 5.9 per cent blade height at the outlet. At the impeller inlet, the hub-tip ratio is 0.315 . The impeller is followed by a pinched, vaneless diffuser with parallel walls. The volute is designed overhung with a smooth-edged, semielliptic tongue.

Both test rig and compressor were built by the National State Key Laboratory for Turbocharging in Shanxi Province, China. The major parameters measured in the performance testing include total/static pressure and temperature at the inlet/outlet of the compressor, mass flowrate, rotational speed, and ambient pressure and temperature. The temperature is measured by thermal couples with an error of less than $\pm 1^{\circ} \mathrm{C}$, the pressure by probes $( \pm 0.2$ per cent), the mass flowrate by a vortex flow meter $( \pm 1.0$ per cent), and the rotational speed by an electromagnetic transducer $( \pm 0.5$ per cent).

\section{VALIDITY OF SIMULATION}

\subsection{Spatial resolution}

Figure 3 shows the performance results at design speed for the two different grid numbers. The spline connects the coarse grid results, while the fine grid results are shown as marks. The predicted characteristics show a satisfying agreement. For a given mass flow, the results never differ by more than 0.646 per cent. At the design point, the relative differences are 0.55 per cent for pressure ratio and 0.44 per cent for efficiency. Numerical instability was found for the same limiting mass flowrate, yet this value was chosen in steps of $0.1 \mathrm{~kg} / \mathrm{s}$. As the additional expenses in computational time necessary to calculate the complete domain with the fine passage mesh are tremendous (6 days per operating point compared to approximately 2 days for the coarse mesh), these uncertainties are accepted. Hence, the lower grid number was used for performance and stability prediction.
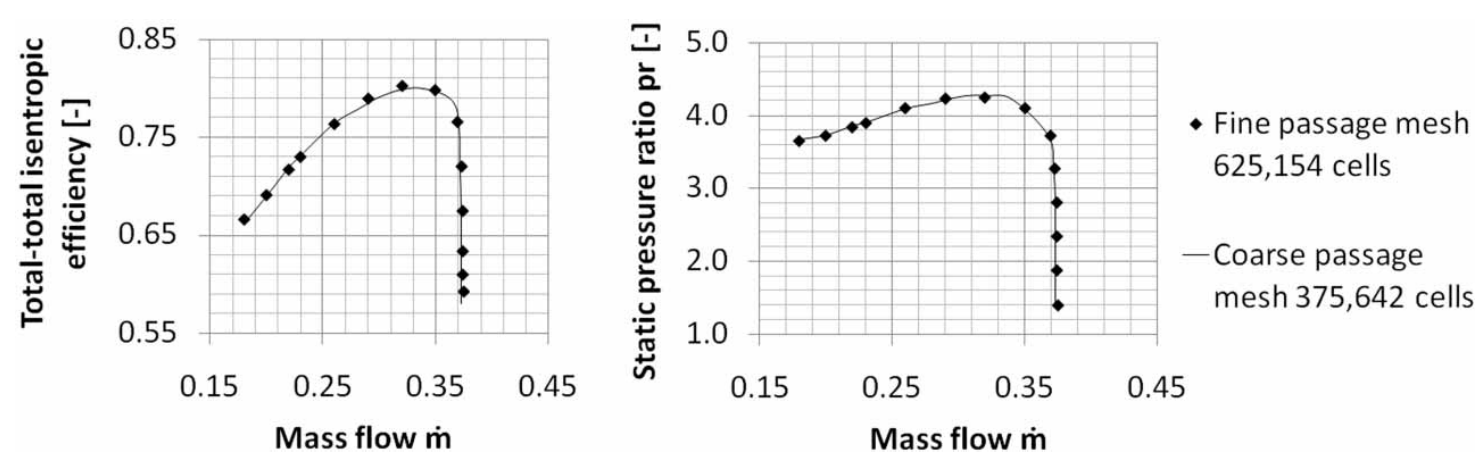

Fig. 3 Grid number validation: performance characteristics for fine (points) and coarse (lines) mesh 


\subsection{Rotor-stator interaction}

The interaction between rotor and stator patches of the grid is one of the key issues in this work. When applying the frozen rotor approach, the results for a low blade number or low rotational speed are likely to exhibit high dependence on the impeller blades' meshed angular position, especially on the position of the blade facing the volute tongue. Fatsis et al. (1997) suggested using the acoustic Strouhal number $\mathrm{Sr}$ to calculate the relative effects of rotation and pressure wave propagation [30]. The dimensionless acoustic $\mathrm{Sr}$ is defined as

$$
S r=\frac{L_{p} f}{c}
$$

It relates the time needed by a pressure wave to travel the passage length $L_{\mathrm{p}}$ with the speed of sound $c$ to the period of the pressure perturbation $1 / f$. Wavelike pressure perturbations are caused by the volute tongue; hence, the frequency $f$ can be set as the rotational speed $N$. Distortion waves of higher frequency, as they were discussed in references [11] and [30], cannot be predicted using the frozen rotor approach. A simulation applying the frozen rotor model is an exact representation of the flow field only in case the Strouhal number is close to zero. In this particular case, $\mathrm{Sr}$ increases from 0.179 at $80000 \mathrm{r} / \mathrm{min}$ up to 0.304 at $136000 \mathrm{r} / \mathrm{min}$, when inlet conditions are used for $c$. The passage length was approximated by

$$
L_{p}=\sqrt{\text { passage_height }^{2}+\text { passage_width }^{2}}
$$

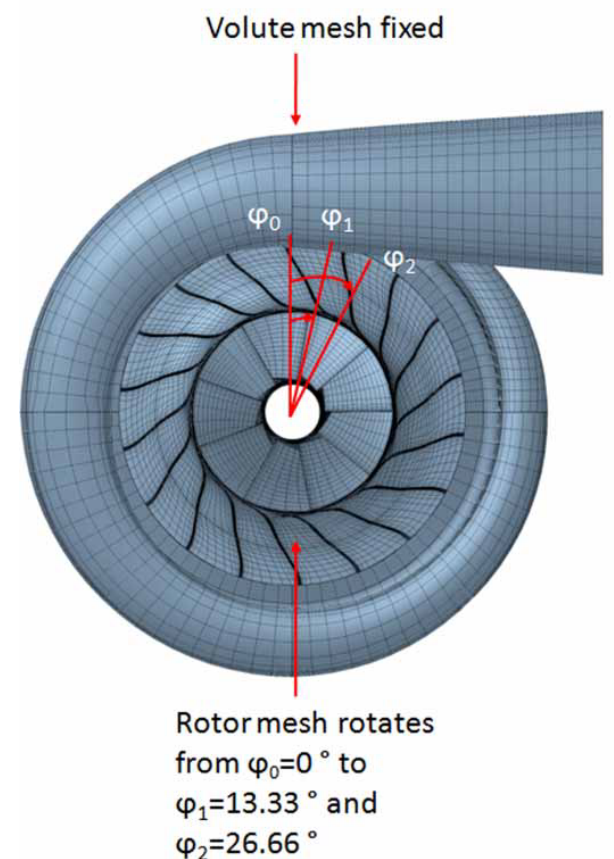

The rotation with design speed is about three times faster than the pressure wave propagation through the blade passage. It can be inferred that the angular position of the rotor indeed has an influence on simulation results. The impact of the rotor position on performance characteristics has to be tested. Fine meshes for three different positions of the rotor were therefore created. The periodicity of the rotor is $40^{\circ}$, and thus the rotor was moved from angle $\varphi$ to $\varphi+13.33^{\circ}$ and $\varphi+26.66^{\circ}$, respectively, as shown in Fig. 4 (left). For procedural reasons, an operation point near the choke limit (backpressure $300 \mathrm{kPa}$ ) was chosen. The performance results for the three different conditions are shown in Fig. 4 (right). The relative errors are 0.03 per cent for total-total pressure ratio, 0.08 per cent for total-static pressure ratio, 0.17 per cent for efficiency, and 0.03 per cent for mass flow, which means that neglecting the influence of the rotor position for the calculation of performance quantities is reasonable.

There are further aspects that have to be considered when applying the frozen rotor approach. A strong wake flow is present in the stationary component that mixes out in reality due to rotor-sided rotation; however, this is of higher importance for centrifugal pumps with short diffuser length. Gu and Engeda (2001) further conclude, from a comparison to measurement results, that the frozen rotor approach is responsible for a simulation not to predict the measured decay of static pressure perturbations when they are propagated upstream in the diffuser [13].

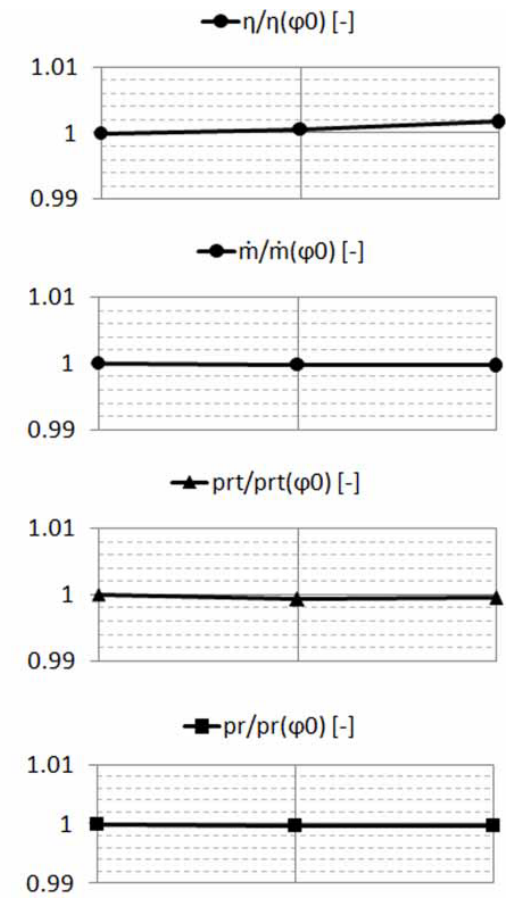

Fig. 4 Different rotor positions $\varphi$ for independence test (left) and influence of rotor position on performance quantities (right) 


\subsection{Comparison with test results}

When performing the simulation of the compressor map, the outlet mass flow was decreased stepwise until the equilibrium in flow quantities according to the convergence criteria was no longer attained. On the finest grid, the simulation was considered as converged if:

(a) all quantities did not vary more than 0.1 per cent over 100 consecutive iterations;

(b) inlet and outlet mass flow levelled off within 0.5 per cent of each other;

(c) the global residual decreased more than three orders of magnitude and reached level.

The operation point with the lowest mass flow that still converged was considered to be the surge point. The resulting surge points were connected to obtain the surge line. It is somehow misleading to conclude from numerical steady-state instabilities to time-dependent system oscillations. These oscillations are caused by instable flow conditions which are believed to be caused by the flow phenomena of the instable subsystem stall (e.g. rotating stall cells) or suddenly increasing blockage, which are among possible triggers of system surge. However, the onset surge is further influenced by many parameters not taken into consideration (piping system, volumes, time dependence, etc.). It is therefore incorrect to conclude the absolute limit of surge from these instabilities, but it is assumed that relative differences in surge limit (i.e. the effect of flow range extension or constriction), can be predicted with certain accuracy. The lower mass flow limit is, in this work, referred to as the surge limit of the CFD calculations, a procedure that is (implicitly or explicitly) common for the investigation of relative effects on the surge limit (for example, see references [31] and [32]).

Figure 5 shows the whole compressor map, including seven speedlines ( $80000-136000 \mathrm{r} / \mathrm{min}$ ) for experiment and CFD. For lower speed, the simulation predicts the performance results precisely regarding performance and limits towards lower and higher mass flow. With increasing rotor speed, the CFD simulation tends to overestimate the total pressure at the outlet, most significant at mass flowrates near the peak total pressure ratio. The main reasons are listed as follows.

1. Available turbulence models are not able to quantify the losses in transonic impeller flow correctly, as concluded before by Krain et al. and later by Guo et al. for the simulation of a transonic compressor's flow field structure by CFD [33-35]. Furthermore,



Fig. 5 Validation of simulation with test bench results: total pressure compressor map for seven different rotor speeds (left), total-to-total isentropic efficiency for three speedlines (top right), and overestimation of peak pressure ratio (relative error over rotational speed $N$; below right) 
the applied S-A model exhibits shortages in the representation of turbulent loss generation. From the efficiency characteristics shown in Fig. 5, it can be seen that the efficiency drop at high speed (transonic inlet conditions are exhibited from $N=$ $130000 \mathrm{r} / \mathrm{min}$ ) is predicted as less severe by the simulation than it is shown in the experimental results.

To validate the methodology to investigate influences on SFR with the S-A model, computations for one speedline were carried out with the twoequation $k-\varepsilon$ model, which is known from the authors experience to deliver better results for the turbulent flow field. Figure 6 shows computed total pressure results for $130000 \mathrm{r} / \mathrm{min}$ of the impeller without the volute the one-equation S-A model and the two-equation $k-\varepsilon$ model with extended wall function. Both characteristics show good agreement at the point of peak total pressure (difference 0.3 per cent). However, the compressor map margin is overestimated to both sides by the S-A model, which is known to be numerically robust. SFR is defined as

$$
\mathrm{SFR}=\left(\frac{m_{\text {choke }}-m_{\text {surge }}}{m_{\text {choke }}}\right)_{N=\text { const }} \times 100 \text { per cent }
$$

The results differ in SFR by 11.27 per cent, which is a significant difference. However, of primary interest is not the absolute value of SFR, but the relative differences at different rotor speed with and without the volute. Further, $\mathrm{Xu}$ and Amano [36] showed that the flow field in the volute is hardly affected by the order of the turbulence model. Since the S-A model features comparably low required CPU time, and regarding the large number of simulations necessary, CPU time was distinctive. Less physical accuracy compared to $k-\varepsilon$ or $k-\omega$ models was therefore accepted.

2. The work input of the impeller is predicted too large by the CFD calculations, which can be seen

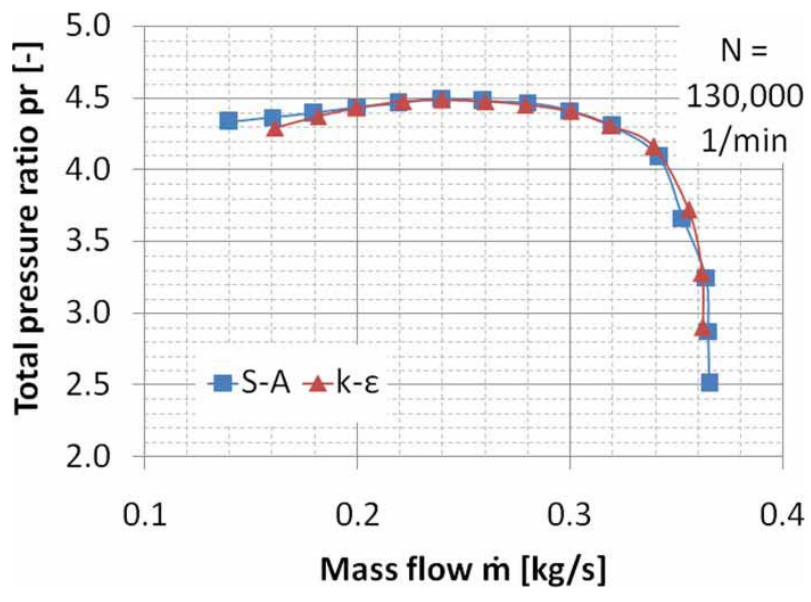

Fig. 6 Performance characteristics of the compressor at $130000 \mathrm{r} / \mathrm{min}$ computed with two different turbulence models in Fig. 5, showing good representation of efficiency characteristics and overestimated total pressure rise. It is supposed that tip clearance was not modelled as large as it was in the experiment. Leakage flow exhibits less turning and, according to the Euler equation, work input is smaller. The error characteristic exhibits only a slight kink at the transition to mainly transonic inlet conditions from $N=110000$ to $120000 \mathrm{r} / \mathrm{min}$. However, if work input was well represented in the simulation, there should be no significant error in total pressure below $120000 \mathrm{r} / \mathrm{min}$. Tip clearance is known to influence high pressure ratio centrifugal compressor performance significantly. For low speed, too high work input is compensated by slightly too low predicted efficiency, which leads to a small error in the total pressure ratio. It is believed that the agreement in pressure ratio can be further improved by modelling changes in tip clearance correctly.

Besides the overall trend, the limits of range are important. For a transonic compressor with vaneless diffuser, the choke limit at low rotor speed is usually determined by the diffuser. At high speed, the inducer of the impeller is choking, which is usually well predicted by CFD. The choke limit at design speed is 1.38 per cent higher in the simulation than in the experiment, which is similar to the error in the results of Kang [37], who used the same CFD code for a transonic impeller. It is supposed that the neglected clearance between impeller and diffuser hub is directly responsible for this difference. Since the main purpose of the work was to investigate the relative influence of on the surge limit, the absolute error for the surge limit is not of primary interest, as it is caused by the systematic error of interpreting numerical instabilities as surge. Nevertheless, the absolute error is relatively small $(\leqslant 6.44$ per cent). Thus, while keeping track of the discussed errors, the results from CFD can be used to discuss (passage) performance and stability of the present compressor.

\section{INFLUENCE OF THE VOLUTE ON COMPRESSOR FLOW}

\subsection{Influences on compressor performance and stability}

To evaluate the influence of the volute on compressor stability and performance, seven speed lines were calculated with both case set-ups. The influence of the volute on overall compressor performance is displayed in the compressor map for total-total pressure ratio in Fig. 7 (left). The efficiency characteristic for the design speed is displayed in Fig. 7 (right).

The main trends of the speedlines remain similar for operation with and without volute. The characteristics 


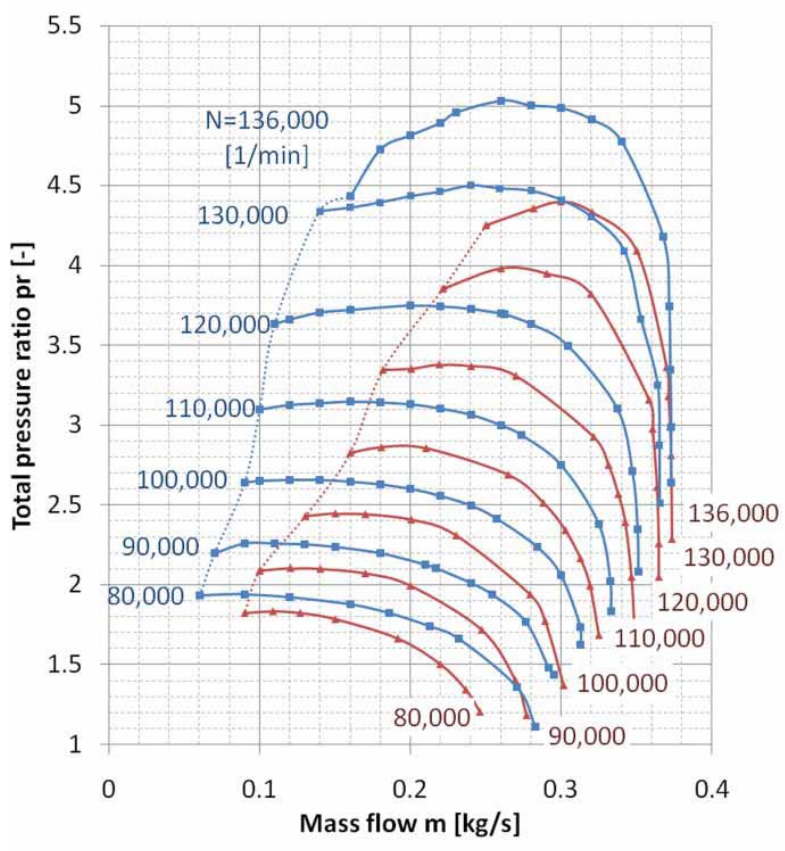

- -Without volute $\quad$-With volute
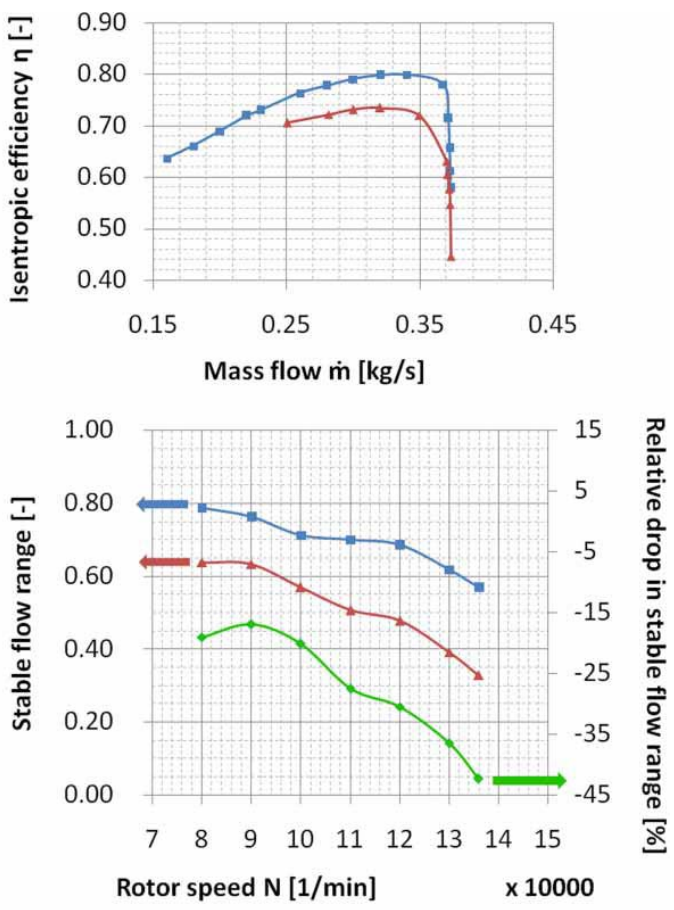

$\rightarrow$ Drop in stable flow range due to volute

Fig. 7 Compressor map for total pressure ratio with and without volute (left), isentropic efficiency over mass flow at design speed (top right), and relative influence of volute on SFR (below right)

for total pressure ratio and efficiency unveil the high losses occurring due to the volute, consisting of losses in the volute itself as well as in impeller and diffuser. The losses in the volute mainly consist of:
(a) friction loss;
(b) swirl loss;
(c) mixing loss;
(d) expansion loss at low mass flow;
(e) expansion loss in the exit cone.

The instantaneous mass flowrate has little influence on (a), (b), and (e). Swirl loss is the major loss factor and is a function of radial diffuser outlet velocity (i.e. of mass flow). Expansion loss decreases up to the design point [3]. Hence, aggregate loss will increase slightly up to the design mass flowrate and spike afterwards, when the choke limit is approached. At the design point, the volute is responsible for a 6.5 per cent drop in efficiency and 11.8 per cent relative drop in total pressure ratio. This deterioration of compressor performance is significant. The volute tongue was not designed as carefully as necessary according to the findings in the literature [21, 22]. The flow exiting the investigated impeller is transonic. It is thus supposed that the performance drop is attributable to the swirl loss caused by high radial outlet velocity and insufficient volute tongue design.

The losses in the vaneless diffuser are hardly affected by the volute. The losses in the impeller due to the volute are small at and near the design point of the volute, which is located at a slightly higher mass flowrate than the point of peak efficiency (refer to Fig. 8). Figure 7 shows increasing total pressure ratio drop at approximately constant relative penalty in efficiency when the flowrate is decreased. Thus, impeller work input is deteriorated. The operation at low mass flow imposes a static pressure profile on the outlet of the impeller passages, which then exhibit a positive slope in the direction of rotation, except those facing the tongue region. This pressure slope causes a more tangential outflow, which according to the Euler equation means lower work input [13]. Thus, the performance results show good agreement with existing work on low pressure ratio compressors.

Beside the drop in total pressure and efficiency, which was already reported in previous works, the most significant influence of the volute found is the effect on SFR. The two characteristics for SFR with and without volute are shown in Fig. 7 (below right) referring to the primary (left) axis. The range of operation decreases for both cases, with and without volute, with increasing rotor speed. However, in case of operation with volute, the range drop is much more severe. The relative difference is displayed by the green characteristic referring to the secondary axis (right). The SFR is constricted by the volute by up to 42 per cent at design speed, with only 19 per cent at $80000 \mathrm{r} / \mathrm{min}$. At design speed, a huge share of the deterioration of SFR of the simulated compressor is due to the instabilities imposed by the perturbations caused by the 
Circumferential angle at impeller outlet (passage center)

(a)

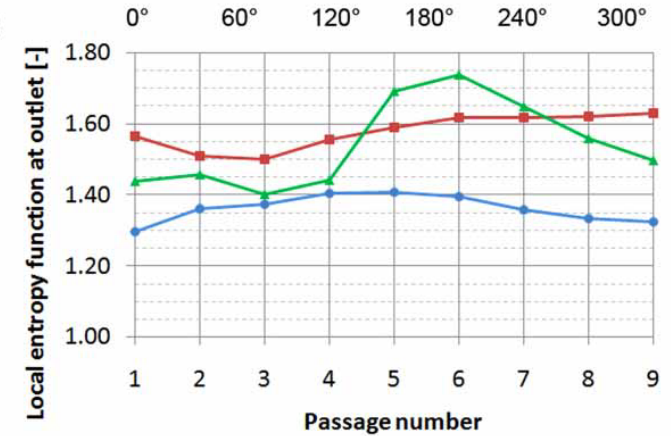

(c)

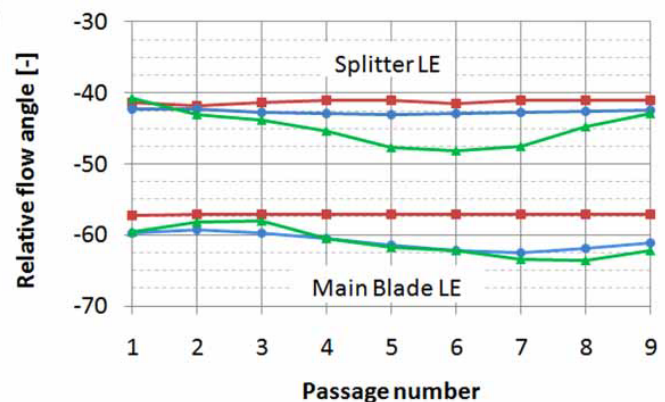

(e)

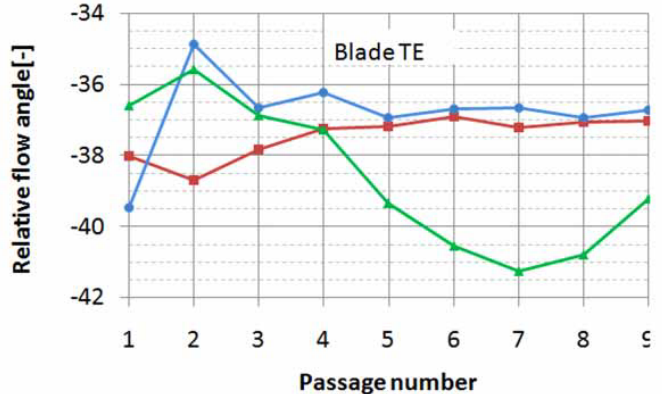

Circumferential angle at impeller outlet (passage center)

(b)

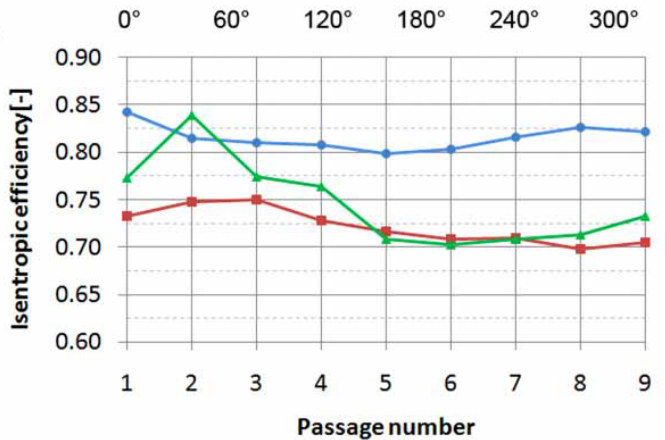

(d)

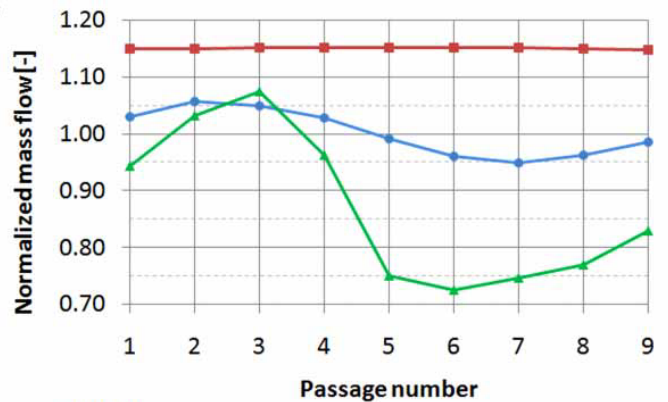

(f)

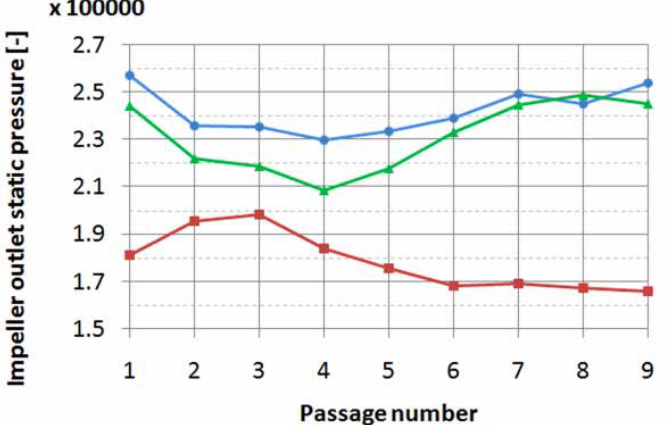

$\rightarrow-$ Near choke $\rightarrow$ Design point $\quad-$ Near surge

Fig. 8 Performance quantities for single passages: (a) local entropy function, (b) isentropic efficiency, (c) inlet relative flow angle, (d) mass flow, (e) outlet relative flow angle, and (f) outlet static pressure

volute. Thus, these perturbations are likely the most important reason for the constricting effect.

For higher rotational speeds, the choke limit is almost equal for operation with and without volute. The volute influence is significant only at the lower limit of numerical instabilities experienced in the calculations. The compressor is driven into surge at much higher mass flows. The reason for the limiting towards lower flowrates is supposed to be the influence of the volute on impeller inlet and outlet conditions [5]. These conditions cause the impeller passage flow to be highly unsteady [13]. However, this does not adequately explain why the influence is dependent on the rotational speed. As discussed above, the flow field of a high pressure ratio centrifugal compressor exhibits a higher sensitivity to blade incidence angle and external distortions. At off-design operation, especially near surge, the volute tongue area seems to cause perturbations that are severe enough to prohibit stable operation of the compressor. However, at lower speed, the influence of the volute gets significant (e.g. increasing the mass flow at the choke line by approximately 20 per cent at $80000 \mathrm{r} / \mathrm{min}$ ).

\subsection{Influences on passage performance}

Figure 8 shows the circumferential distribution of performance and flow parameters for the nine impeller passages. The passage facing $\Theta=0^{\circ}$ is named passage 1; the following eight passages are numbered in the direction of rotation (see Fig. 2, below right). Each passage consists of one main blade passage, which is divided by one splitter blade. All values are averaged on surfaces normal to the meridional direction. Flow angle distributions at the inlet are averaged on surfaces at -2.5 per cent meridional distance. Loss generation 
is quantified by the local entropy function $s^{*}$, which was introduced in reference [38]

$$
s^{*}=\mathrm{e}^{\Delta S / c_{p}}=\frac{\left(T_{\mathrm{t}} / T_{\mathrm{t} 0}\right)^{\gamma / \gamma-1}}{p_{\mathrm{t}} / p_{\mathrm{t} 0}}
$$

The characteristics are edited as it was done by $\mathrm{Gu}$ and Engeda (2001), yet the only detailed analysis of single passage performance characteristics under influence of the volute. The pressure distribution in the volute imposes a static pressure slope on the impeller outlet. The aforementioned authors point out that facing a positive static pressure slope causes increased loss in the impeller and is the main reason for the performance drop of a low pressure ratio compressor at off-design. The affected passages near the choke are only those upstream of the volute tongue, at near surge operations all passages except for them. The averaged pressure rise from the pressure side to the suction side of the blades causes a strong deterioration of the flow, which leaves the impeller with high tangential velocity. Hence, passage losses rise and efficiency alleviates [13].

In the presented compressor flow, the blockage in the diffuser due to the tongue region shifts the point of lowest pressure in the direction of rotation downstream, so that the static pressure discontinuity at the tongue is extended to a region of negative slope (see Fig. 8(f)). There are three passages facing a clear negative gradient at the outlet (1-3). However, it can be seen that indeed those passages located at a clear positive slope of impeller outlet static pressure (Fig. 8(f)), passages 5-7, are those with the most tangential outflow (largest absolute outflow angle, Fig. 8(c)), which indicates deteriorated passage performance. This can be seen from the lowest values for efficiency (Fig. 8(b)) and mass flow (Fig. 8(d)). Especially the flow in the passages 5 and 6 seems to exhibit high losses, as it is indicated by the largest values for local entropy function (Fig. 8(a)). The relative flow angle in these two passages is larger (more work input) and efficiency lower than in passage 7 , so that absolute loss generation must be extraordinarily large. Beside those passages facing a clearly positive static pressure slope, the operation of passages eight to nine seem deteriorated. The simple relation of positive static pressure slope enhancing performance, and in turn negative slope deteriorating performance, is not true for the present compressor. Further research on the detailed flow field in the impeller is necessary to understand the mechanisms leading to different performance characteristics of the passages.

It can be seen in Fig. 7 that serious instabilities narrowing the stable operation range are caused by the volute at high pressure ratio. It is obvious from the analysis of the flow field that the asymmetrical influence of the volute is present up to the flow upstream of the impeller. The simulation results approximate a series of operation conditions exhibited by a single passage during one rotation with the frozen rotor approach. In Fig. 8, it can easily be seen that these inlet and outlet operation conditions, as well as the corresponding performance quantities, vary widely for design and off-design points. In fact, the whole flow field is much distorted. Near surge, the mass flow difference is as high as 23.4 per cent of the average. Although this relative difference for the flowrate is remarkable, it is still in quantitative agreement with the results reported for low pressure ratio compressors. The maximum relative differences in efficiency (12.4 per cent) and main blade incidence angle (4.22 per cent relative to average) are significantly larger than in the results reported before.

Since the incidence angle at the surge line is generally smaller for transonic inflow conditions, the influence of the volute on the inflow angle was further investigated. Therefore, near surge operation points for different rotor speeds were compared concerning this variation. The results are presented in Fig. 9, which shows a correlation of third order between the standard deviation of incidence the incidence angle averaged over each passage (as indicator for the incidence variation) and rotor speed. It has to be noted that, except the design speed, all results were obtained from the coarse grid simulations, but it can be assumed that the results are valid in qualitative dimension. Further, the flow at the inlet of the presented impeller is designed transonic even at near surge operation points to achieve a high pressure ratio. This makes the flow more sensitive to incidence variations. Thus, in addition to the higher sensitivity to incidence angle due to higher Mach number, the relative variations of incidence angle due to the volute at the surge line increase with rotor speed. The incidence angle at the main blade and splitter blade LE varies in the sequence and is hence supposed to cause laminar blade separation and further large tip leakage mass flow due to pressure difference between pressure and suction side. Interaction of the tip leakage vortex with

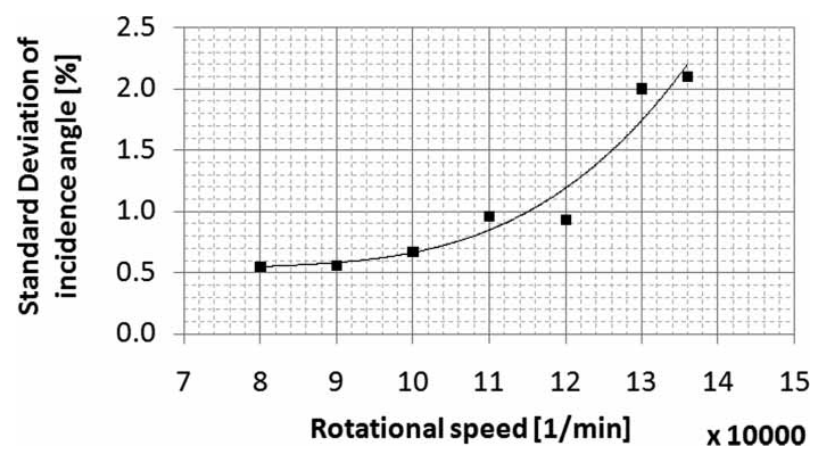

Fig. 9 Standard deviation of incidence angle (with third-order polynomial trend line) for different rotor speeds 
the shock wave and the casing boundary layer and subsequent breakdown of the vortex in the splitter passage is one of the main triggers of stall for a transonic compressor $[\mathbf{3 5}, \mathbf{3 8}, \mathbf{3 9}]$. Thus, a large variation of incidence angle exhibited by one passage during one rotation is supposed to be the reason for more severe relative drop in efficiency and SFR (as shown in Fig. 7) for high rotor speed.

\subsection{Pressure wave propagation}

As mentioned above, a simulation with frozen rotor is not able to predict the decay of the pressure distortions in the diffuser, which means that the real variations will be less severe. The calculation of the Strouhal number $\mathrm{Sr}$ above delivers more insights than just the fact that the results are dependent on rotor position. The Strouhal number also indicates how the real flow field is influenced by the static pressure excitation at the passage outlet. The pressure wave originating at the impeller outlet travels through the impeller passage and is reflected at the splitter and main blade inlet. The fact that $\mathrm{Sr}$ approaches 0.5 means that the time of rotation, the reciprocal frequency of pressure perturbations at the outlet, approaches the time the pressure wave needs to travel twice through the passage (i.e. the resonance case). The calculation of $\mathrm{Sr}$ is only an approximation, but it indicates that the frozen rotor approach has only limited capability to predict the flow field in the impeller accurately. The time-dependent interference of these pressure waves and their amplification by resonance is neglected completely. This and the limited capability of the S-A model to represent turbulent flow make the presented results exhibit limited accuracy in the prediction of the instantaneous flow field and in inter-passage variations.

\section{CONCLUSION AND IMPLICATIONS}

In the present work, the asymmetric influence of the volute on the flow field of a high-pressure ratio, transonic compressor at off-design conditions and their impact on SFR were addressed. The created mesh was found to present results independent of spatial discretization refinement. It can be shown that, when using the frozen rotor approach, the rotor position has negligible influence on performance parameters. The simulation was verified using experimental results from a turbocharger test bench, accepting errors in insufficient prediction of losses at high rotor speed and underestimation of tip leakage. Based on this validation, the following conclusions and implications can be drawn from the simulation results.

1. The volute was found to severely limit flow stability when operating at lower than design mass flow. The relative influence of the volute on SFR was found to correlate with rotational speed and therewith pressure ratio. The relative constriction in SFR increases up to 42 per cent at design speed. This makes the volute and its mainly $N$-periodic, asymmetric perturbations a major constricting factor for the SFR of a centrifugal compressor with high pressure ratio and transonic inflow.

2. A correlation of relative incidence angle variation due to the volute with rotor speed and the higher sensitivity to incidence angle variations of the transonic compressor are supposed to be responsible for the more severe effect of the volute on SFR. These counteracting effects seem to be the reason for significantly higher losses in some passages at high pressure ratio. As the underlying flow mechanisms are not yet fully understood, a comprehensive investigation of the detailed flow field in a transonic high pressure ratio compressor followed by a volute is necessary.

3. When attempting to enhance the map width of a transonic centrifugal compressor, the asymmetric influence of the volute has to be considered. Based on the understanding of the asymmetric flow mechanisms, corresponding asymmetric flow control methods may be developed to counteract the volute's influence.

4. To gain further understanding about which flow mechanisms lead to the performance variations between the single passages, a thorough analysis of the flow field is necessary. Steady simulation with the frozen rotor fails to represent the decay of distortions as they are transmitted upstream in the diffuser. Further, the flow field in the impeller is governed by pressure wave propagation and reflection in the blade-to-blade channels and the excitation frequency is in the order of magnitude for resonance. Thus, a steady-state simulation under the given conditions is unlikely to predict the instantaneous detailed flow field accurately. However, understanding the flow mechanisms leading to instabilities is of utmost importance to draw implications for compressor design. That is, unsteady simulation of a high pressure ratio compressor including a volute is necessary for further steps.

\section{ACKNOWLEDGEMENT}

This research was supported by National Natural Science Foundation of China (Project No. 50806040).

(C) Authors 2010

\section{REFERENCES}

1 Hayami, H. Research and development of a transonic turbo compressor. In Turbomachinery and heat transfer 
(Ed. H. Chunill), 1997, pp. 63-82 (Marcel Dekker Inc., New York).

2 Ayder, E. and den Braembussche, R. V. Experimental study of the swirling flow in the internal volute of a centrifugal compressor. ASME paper no. 91-GT-7, 1991.

3 Ayder, E. Experimental and numerical analysis of the flow in centrifugal compressor and pump volutes. $\mathrm{PhD}$ Thesis, Universiteit Gent and VKI, 1993.

4 Ayder, E., den Braembussche, R. V., and Brasz, J. J. Experimental and theoretical analysis of the flow in a centrifugal compressor volute. J. Turbomach., 1993, 115, 582-589.

5 Sorokes, J., Borer, C., and Koch, J. Investigation of the circumferential static pressure non-uniformity caused by a centrifugal compressor discharge volute. ASME paper no. 98-GT-326, 1998.

6 Hagelstein, D., den Braembussche, R. V., Keiper, R., and Rautenberg, M. Experimental investigation of the circumferential pressure distortion in centrifugal compressor stages. ASME paper no. 97-GT-50, 1997.

7 Den Braembussche, R. V. and Haendel, B. Experimental and theoretical study of the swirling flow in centrifugal compressor volutes. J. Turbomach., 1990, 112, 38-43.

8 Den Braembussche, R. V., Ayder, E., Hagelstein, D., Rautenberg, M., and Keiper, R. Improved model for the design and analysis of centrifugal compressor volutes. $J$. Turbomach., 1999, 121, 619-625.

9 Ayder, E. Numerical analysis of the three-dimensional swirling flow in centrifugal compressor volutes. J. Turbomach., 1994, 116, 462-467.

10 Flathers, M. and Bache, G. Aerodynamically induced radial forces in a centrifugal gas compressor - part 2: computational investigation. ASME paper no. 96-GT352, 1996.

11 Hillewaert, K. and den Braembussche, R. V. Numerical simulation of impeller-volute interaction in centrifugal compressor. J. Turbomach., 1999, 121, 603-608.

12 Gu, F., Engeda, A., Cave, M., and Di Liberti, J.-L. A numerical investigation on the volute/diffuser interaction due to the axial distortion at the impeller exit. J. Fluids Eng., 2001, 123(3), 475-483.

13 Gu, F. and Engeda, A. A numerical investigation on the volute/impeller steady-state interaction due to circumferential distortion. ASME paper no. 2001-GT-0328, 2001.

14 Sorokes, J. and Koch, J. The influence of low solidity vaned diffusers on the static pressure non-uniformity caused by a centrifugal compressor discharge volute. ASME paper no. 2000-GT-0454, 2000.

15 Steglich, T., Kitzinger, J., Seume, J. R., den Braembussche, R. V., and Prinsier, J. Improved diffuser/volute combinations for centrifugal compressors. ASME paper no. GT2005-68894, 2005.

16 Pan, D., Whitfield, A., and Wilson, M. Design considerations for the volutes of centrifugal fans and compressors. Proc. IMechE, Part C: J. Mechanical Engineering Science, 1999, 213, 401-410. DOI: 10.1243/0954406991522356.

17 Reunanen, A. Experimental and numerical analysis of different volutes in a centrifugal compressor. $\mathrm{PhD}$ Thesis, Lappeenranta University of Technology, Lappeenranta, 2001.

18 Hassan, A. S. Influence of the volute design parameters on the performance of a centrifugal compressor of an aircraft turbocharger. Proc. IMechE, Part A: J. Power and Energy, 2006, 221, 695-704. DOI: 10.1243/ 09576509JPE436.

19 Dai, Y., Engeda, A., Cave, M., and Di Liberti, J.-L. Numerical study and experimental validation of the performance of two different volutes with the same compressor impeller. Proc. IMechE, Part B: J. Engineering Manufacture, 2009, 223, 157-166. DOI:10.1243/09576509JPE676.

20 Dai, Y., Engeda, A., Cave, M., and Di Liberti, J.-L. A flow field study of the interaction between a centrifugal compressor impeller and two different volutes. Proc. IMechE, Part A: J. Power and Energy, 2010, 224, 345-356. DOI: 10.1243/09544062JMES1522.

$21 \mathrm{Xu}, \mathrm{C}$. and Amano, R. Eliminating static pressure distortion by a large cut back tongue volute. ASME paper no. GT2006-90001, 2006.

$22 \mathrm{Xu}, \mathrm{C}$. and Mueller, M. Development and design of a centrifugal compressor volute. Int. J. Rotat. Mach., 2005, 3, 190-196.

23 Jameson, A. and Baker, T. Solutions of the Euler equations for complex configurations. AIAA paper no. 831929, 1983.

24 Jameson, A., Schmidt, W., and Turkel, E. Numerical solutions of the Euler equations by finite volume methods using Runge-Kutta time stepping schemes. AIAA paper no. 81-1259, 1981.

25 Martinelli, L. Calculations of viscous flows with a multigrid method. PhD Thesis, Princeton University, 1987.

26 Vatsa, V. and Wedan, B. Development of an efficient multigrid code for 3-D Navier-stokes equations. AIAA paper no. 89-1791, 1989.

27 Spalart, P. and Allmaras, S. A one equation turbulence model for aerodynamic flows. AIAA paper no. 92-0439, 1992.

28 Ashford, G. and Powell, K. An unstructured grid generation and adaptative solution technique for highReynolds number compressible flow. Lecture Series 1996-06, VKI (Von Karman Institute), 1996.

29 NUMECA International. NUMECA FINE/Turbo User Manual 7.1, 2006 (NUMECA International, Belgium). Available from www.numeca.com.

30 Fatsis, A., Pierret, S., and den Braembussche, R. V. Three-dimensional unsteady flow and forces in centrifugal impellers with circumferential distortion of the outlet static pressure. J. Turbomach., 1997, 119, 94-102.

31 Hunziker, R., Dickmann, H.-P., and Emmrich, R. Numerical and experimental investigation of a centrifugal compressor with an inducer casing bleed system. Proc. IMechE, Part A: J. Power and Energy, 2001, 215, 783-791. DOI: 10.1243/0957650011538910.

32 Yamaguchi, S., Yamaguchi, H., Goto, S., Nakao, H., and Nakamura, F. The development of effective casing treatment for turbocharger compressors. In Proceedings of the 7th International Conference on Turbochargers and turbocharging, IMechE C602/008/2002, 2002.

33 Krain, H., Hoffmann, B., Rohne, K.-H., Eisenlohr, G., and Richter, F.-A. Improved high pressure ratio centrifugal compressor. ASME paper no. GT2007-27100, 2007.

34 Krain, H., Karpinski, G., and Beversdorff, M. Flow analysis in a transonic centrifugal compressor rotor using 3-component laser velocimetry. ASME paper no. 2001-GT-0315, 2001. 
35 Guo, G., Zhang, Y., Xu, J., Zheng, X., and Zhuge, W. Numerical simulation of a transonic centrifugal compressor blades tip clearance flow of vehicle turbocharger. ASME paper no. GT2008-50957, 2008.

$36 \mathrm{Xu}$, C. and Amano, R. S. Computational analysis of scroll tongue shapes to compressor performance by using different turbulence models. ASME paper no. GT2007-28224, 2007.

37 Kang, S. Numerical investigation of a high speed centrifugal compressor impeller. ASME paper no. GT200568092, 2005.

38 Ibaraki, S., Furukawa, M., Iwakiri, K., and Takahashi, K. Vortical flow structure and loss generation process in a transonic centrifugal compressor impeller. ASME paper no. GT2007-27791, 2007.

39 Hazby, H. and Xu, L. Role of tip leakage in stall of transonic centrifugal compressor. ASME paper no. GT200959372, 2009.

\section{APPENDIX}

\section{Notation}

$c \quad$ local speed of sound ( $\mathrm{m} / \mathrm{s})$

$C_{p} \quad$ specific heat at constant pressure $(\mathrm{kJ} / \mathrm{kg})$ impeller outer diameter (m)

Euler number

e

$f$

frequency of rotation/excitation frequency of pressure distortion (r/min)

$L_{p} \quad$ approximated passage length (m)

$\dot{m} \quad$ (corrected) mass flow $(\mathrm{kg} / \mathrm{s}$ )

$N \quad$ rotational speed (r/min)

$p \quad$ static pressure $(\mathrm{Pa})$

pr static pressure ratio

$\mathrm{pr}_{\mathrm{t}} \quad$ total pressure ratio

$p_{\mathrm{t}} \quad$ total pressure $(\mathrm{Pa})$

$s \quad$ entropy $(\mathrm{kJ} / \mathrm{kg} \mathrm{K})$

$s^{*} \quad$ local entropy function

$t \quad$ tip clearance $(\mathrm{m})$

$T_{\mathrm{t}} \quad$ total temperature (K)

$y_{1}^{+} \quad$ non-dimensional wall distance of first node

$y_{\text {wall }} \quad$ wall distance of the first node (m)

$\gamma \quad$ specific heat ratio

$\eta \quad$ total-to-total efficiency

$\theta \quad$ circumferential angle (degree)

$\varphi \quad$ angle of rotor position (degree) 
